\title{
Changes in viscoelastic vibrational properties between compression and normal wood: roles of microfibril angle and of lignin
}

\author{
Iris Brémaud ${ }^{1, a, *}$, Julien Ruelle ${ }^{2}$, Anne Thibaut ${ }^{2,3}$ \\ and Bernard Thibaut ${ }^{1,4}$ \\ ${ }^{1}$ Laboratoire de Mécanique et Génie Civil (LMGC), \\ CNRS, Université Montpellier 2, France \\ ${ }^{2}$ CIRAD, UMR EcoFoG, Kourou, France \\ ${ }^{3}$ CIRAD, UR 40, Production et Valorisation des Bois \\ Tropicaux, Montpellier, France \\ ${ }^{4}$ CNRS, UMR EcoFoG, Kourou, France \\ * Corresponding author. \\ Laboratoire de Mécanique et Génie Civil (LMGC), CNRS UMR- \\ 5508, Université Montpellier 2, cc 048, Place Eugène Bataillon, \\ 34095 Montpellier Cedex 5, France \\ E-mail: iris_bremaud@hotmail.com
}

\begin{abstract}
This study aims at better understanding the respective influences of specific gravity $(\gamma)$, microfibril angle (MFA), and cell wall matrix polymers on viscoelastic vibrational properties of wood in the axial direction. The wide variations of properties between normal wood (NW) and compression wood (CW) are in focus. Three young bent trees (Picea abies, Pinus sylvestris and Pinus pinaster), which recovered verticality, were sampled. Several observed differences between NW and CW were highly significant in terms of anatomical, physical $(\gamma$, shrinkage, CIELab colorimetry), mechanical (compressive strength), and vibrational properties. The specific dynamic modulus of elasticity $\left(E^{\prime} / \gamma\right)$ decreases with increasing MFA, and Young's modulus $\left(E^{\prime}\right)$ can be satisfactorily explained by $\gamma$ and MFA. Apparently, the type of the cell wall polymer matrix is not influential in this regard. The damping coefficient $(\tan \delta)$ does not depend solely on the MFA of NW and $\mathrm{CW}$. The $\tan \delta-E^{\prime} / \gamma$ relationship evidences that, at equivalent $E^{\prime} / \gamma$, the $\tan \delta$ of $\mathrm{CW}$ is approximately $34 \%$ lower than that of NW. This observation is ascribed to the more condensed nature of $\mathrm{CW}$ lignins, and this is discussed in the context of previous findings in other hygrothermal and time/frequency domains. It is proposed that the lignin structure and the amount and type of extractives, which are both different in various species, are partly responsible for taxonomy-related damping characteristics.
\end{abstract}

Keywords: compression wood $(\mathrm{CW})$; damping coefficient; FT-IR; internal friction; lignin; microfibril angle (MFA);

aPresent address: Wood Laboratory, Empa - Swiss Federal Laboratories for Materials Science and Technology, Überlandstrasse 129, CH-8600 Dübendorf, Switzerland.
Picea abies; Pinus pinaster; Pinus sylvestris; specific dynamic modulus of elasticity; viscoelastic vibrational properties.

\section{Introduction}

Wood is a cellular and composite material. Its macroscopic properties depend on porosity and on the orientation of reinforcing elements. The viscoelastic behavior of wood is due to its composite polymeric nature consisting of crystalline cellulosic microfibrils (MFs) embedded in a more or less amorphous matrix (Salmén and Burgert 2009; Stevanic and Salmén 2009). Specific gravity $(\gamma)$, which is inversely proportional to porosity, determines the axial Young's modulus ( $E$ or $E^{\prime}$ in dynamic tests) to a large extent, i.e., it explains approximately $65 \%$ of variability in $E$ over several hundred species, with $\gamma$ ranging from 0.1 to 1.4 (Brémaud et al. 2009; unpublished database at CIRAD). The residual variability mainly expresses variations at the cell wall level. Axial vibrational properties of wood [specific modulus of elasticity $(E / \gamma)$ and damping coefficient $(\tan \delta)]$ are theoretically independent of specific gravity and shall be proportional to cell wall properties. The microfibril angle (MFA) is the main parameter influencing $E / \gamma$ in the wide range of observed MFA values. Various models have been developed to describe this dependency (Norimoto et al. 1986; Koponen et al. 1989; Astley et al. 1998; Bergander and Salmén 2002; Yamamoto and Kojima 2002; $\mathrm{Xu}$ and Liu 2004). Although models differ in their formulation, the relationship between $E / \gamma$ and the MFA $\phi$ has a more or less sigmoid shape, which can be approximated by:

$E / \gamma=1 /\left(a \times \cos ^{4} \phi+b \times \cos ^{2} \phi \sin ^{2} \phi+c \times \sin ^{4} \phi\right)$

Viscoelastic damping of vibration $(\tan \delta)$ in the audiofrequency domain $(\approx 0.1-10 \mathrm{kHz})$ is also known to be strongly dependent on MFA (Norimoto et al. 1986; Obataya et al. 2000). However, much fewer micromechanical models were developed due to a lack of experimental data on viscoelasticity of wood constituents in this frequency range. The fact that both $E^{\prime} / \gamma$ and $\tan \delta$ depend on MFA, is translated in a relationship between these two properties with a shape close to a power law. The empirical curve obtained by Ono and Norimoto (1983) can be used as a standard reference, to which new experimental results can be compared:

$\tan \delta_{s}=10^{-A} \times\left(E^{\prime} / \gamma\right)^{-B}$

where coefficients $A$ and $B$ are 1.23 and 0.68 , respectively, from more than 1200 specimens belonging to 25 softwood species (Ono and Norimoto 1983). It has also been proven 
that chemical composition of extractives, which are acting as "natural chemical modifiers", leads to some shifts of the $\tan \delta-E^{\prime} / \gamma$ curve, either upwards or downwards (Obataya et al. 2000; Brémaud et al. 2010a,b, 2011a, 2012). The influence of extractives explains the differences in tan $\delta$ that are observed between sapwood and heartwood in the same tree (Yano 1994; Brémaud 2006; Brémaud et al. 2011a, 2012), which have essentially the same chemical composition of the cell wall matrix in terms of hemicelluloses and lignin.

In conifers, compression wood (CW) is known to be very different from normal wood (NW) in terms of specific gravity, MFA, and polymeric composition, while the extractives are quite similar (Timell 1982; Yeh et al. 2006; Diaz-vaz et al. 2009). Juvenile wood (JW) of conifers is also quite different from mature NW in terms of specific gravity and MFA. However, the difference in chemical composition between JW and mature wood is not as much as that between $\mathrm{CW}$ and NW (Yeh et al. 2005, 2006; Nanayakkara 2007). The chemical composition of opposite wood (OW) has high similarity to NW in the same log (Timell 1973, 1982; Yeh et al. 2006; Nanayakkara 2007). In summary, CW contains less cellulose (approx. 10\%) and less crystalline moiety. Accordingly, the moiety of the amorphous matrix is $10 \%$ higher, mainly due to increased lignin content (Timell 1982). Changes in hemicelluloses of $\mathrm{CW}$ are mostly of a qualitative nature; for example, the galactoglucomannans are partly substituted by galactans. Increased lignification of the secondary cell wall (S2) is the first symptom of CW formation (Donaldson et al. 2004). In CW lignin, the content in $p$-hydroxyphenyl (H) units is significantly higher (up to $30 \%$ ), which is present only in traces in NW lignins (Timell 1982; Yeh et al. 2005, 2006; Nanayakkara et al. 2009). The peculiarities of $\mathrm{CW}$ were also demonstrated by gene expression studies during wood formation (Yamashita et al. 2009). In general, CW attracted a lot of attention also in the last decade concerning lignin deposition in the S2 layer (Yoshizawa et al. 1999), air permeability (Tarmian and Perré 2009), lignin structure (Önnerud 2003), shear strength (Gindl and Teischinger 2003), morphological and chemical variations (Yeh et al. 2006), characterization of galactans by immunofluorescence (Altaner et al. 2007), relation of MFA and lignin content (Jungnikl et al. 2008), and ultrastructure (Hänninen et al. 2012), just to mention a few. Thus CW is well known and the pair CW/NW is well suited for the investigation of the combined influence of specific gravity, MFA, and chemistry of the cell wall polymers on mechanical properties of wood.

Considerable research has been conducted on physical or elastic mechanical properties of $\mathrm{CW}$, but its dynamic viscoelastic behavior was seldom addressed. Matsumoto (1961) and Norimoto et al. (1984) studied the dynamic properties of air-dry $\mathrm{CW}$ in the acoustic range around $0.1-10 \mathrm{kHz}$. However, the $\mathrm{CW}$ sampling in the quoted papers was limited and the data were not related to microstructural or physicochemical parameters.

The present study is dedicated to the vibrational properties of $\mathrm{CW}$ and attempts to find correlations to other parameters. The focus is on the respective influences of microstructure and of matrix composition on viscoelastic vibrational properties of wood. The hypothesis was that clear results would be obtained, as in $\mathrm{CW}$ several parameters are clearly different from those of NW.

\section{Materials and methods}

\section{Plant material and sampling of test specimens}

Three young trees, Norway spruce (Picea abies [L.] Karst.), maritime pine (Pinus pinaster Aiton.) and Scots pine (Pinus sylvestris L.), [21, 9 and 13 annual rings, respectively, at diameter at breast height (DBH)] were sampled with DBH ranging from 20 to $25 \mathrm{~cm}$. The trees were grown in the region of Bordeaux, France. They had been strongly inclined because of a strong storm which occurred 10 years ago, and then recovered verticality on their upper part. In situ measurements of maturation strains proved that the lower part of their trunk was in a high compressive stress state (Alméras et al. 2005). The expectation, that this section should contain CW, was fulfilled. After cutting a small $\log (50 \mathrm{~cm}$ long $)$ just below the growth strain measurement level, the occurrence of $\mathrm{CW}$ was verified by visual observation (Figure 1a). Anatomical observations on safranin stained thin slides (Figure 1b) confirmed the pure CW character of zones appearing as dark-red macroscopically, while other pale zones are for NW. From these small logs, longitudinal rods $\left(20 \times 20 \times 360 \mathrm{~mm}^{3} ; \mathrm{R} \times \mathrm{T} \times \mathrm{L}\right)$ were cut and air-dried (down to equilibrium at $20^{\circ} \mathrm{C}$ and $65 \% \mathrm{RH}$ ) to perform standard physical and mechanical measurements. Some of these rods were selected as representative of CW (16) and NW (14), respectively (Figure 1a). Thirty shorter rods $\left(20 \times 20 \times 150 \mathrm{~mm}^{3} ; \mathrm{R} \times \mathrm{T} \times \mathrm{L}\right)$ were taken from the long ones and cut into 2 smaller strips per rod $\left(12 \times 2 \times 150 \mathrm{~mm}^{3}\right.$; $\mathrm{R} \times \mathrm{T} \times \mathrm{L})$. These radial strips systematically included both earlywood and latewood (Figure 2).

\section{Microfibril angle (MFA)}

Mean MFA was measured for each rod by the iodine crystals procedure (Senft and Bendtsen 1985). Thick radial sections $(15 \mu \mathrm{m})$ were cut and stored in 50\% ethanol solution. Sections were dehydrated in absolute ethanol for $5 \mathrm{~min}$ twice, and then immersed in a $2 \%$ solution of iodine-potassium iodide for $5 \mathrm{~s}$. Finally, the sections were placed on a slide before adding one or two drops of $60 \%$ nitric acid. Observations were performed on three pictures of $112 \times 84 \mu \mathrm{m}^{2}$ per specimen at a $500 \times$ magnification. Each picture contained approximately 10 tracheids and the measurement was done on approximately 80 MFs per specimen (Figure 1c). Standard deviation of MFA measurements within a specimen was of $4.2 \pm 0.6^{\circ}$, irrespective of species or wood type.

\section{Color}

Colorimetric parameters were measured on the RL surfaces of the $2 \mathrm{~mm}$ thick strips with spectrophotometer Microflash 200d (Datacolor, NJ, USA) with an aperture diameter of $8.7 \mathrm{~mm}$, using CIE standard observer $10^{\circ}$ (color matching function for $10^{\circ}$ angle of vision) and illuminant A (corresponding to incandescent light). Measurements were conducted within a few days after cutting of the specimens, with 3 repetitions per specimen. Data were collected in the CIE $L a b$ system, where $L^{*}$ is lightness ( $0=$ black, $100=$ white), $a^{*}$ is the green (-) to red (+) axis and $b^{*}$ is the blue (-) to yellow $(+)$ axis. 
a
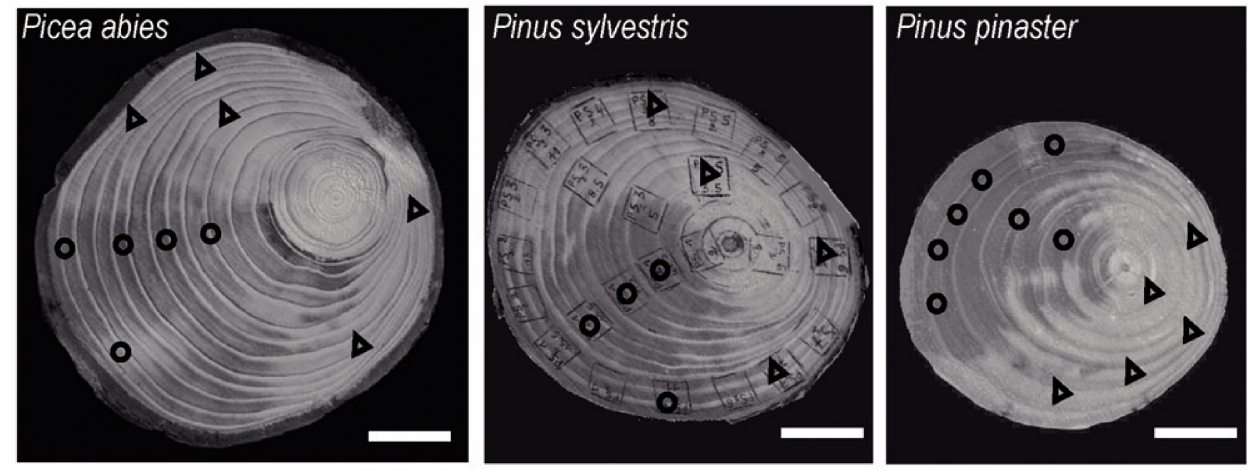

b
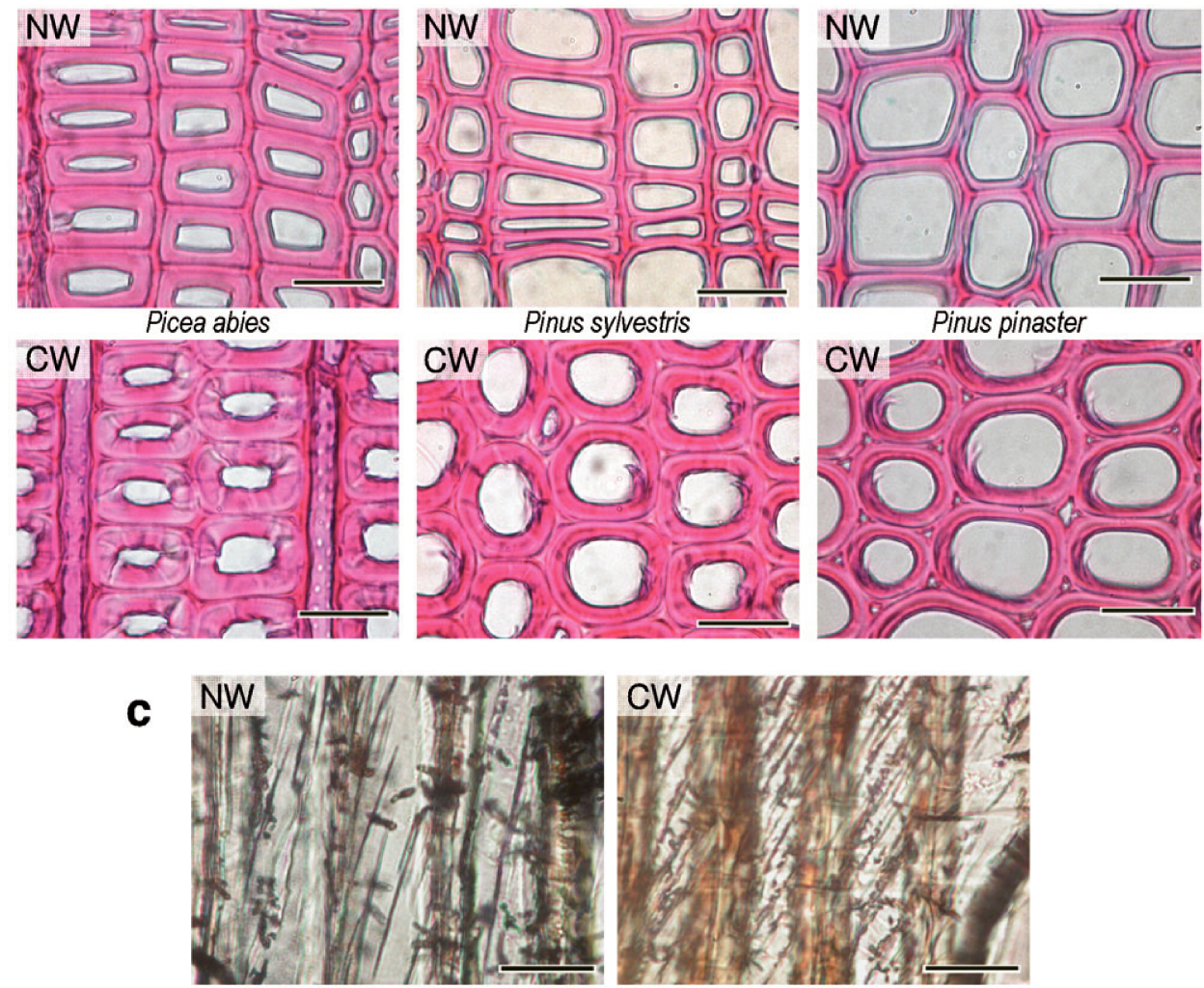

Figure 1 Macroscopic and microscopic description of investigated wood material.

(a) Localization of sampled rods inside the studied trees (Picea abies, Pinus sylvestris and Pinus pinaster). Circles: compression wood (CW); triangles: normal wood (NW). CW sector is always positioned on the left part of the pictures. Scale bars: $5 \mathrm{~cm}$; (b) microscopic observations of anatomy in transverse plane of CW and NW. Staining with safranin. $\times 500$. Scale bars: $25 \mu \mathrm{m}$; (c) example of measurement of MFA on $P$. abies tracheids of normal wood (left, MFA $=22.6^{\circ}$ ) and compression wood (right, mean MFA $=32.4^{\circ}$ ). $\times 500$. scale bars: $25 \mu \mathrm{m}$.

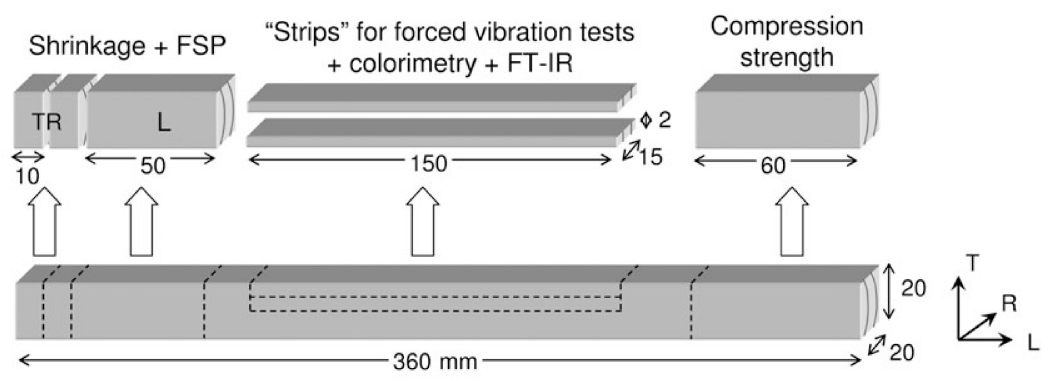

"Rods" for natural vibration tests

Figure 2 Cutting plan of specimens for the different physical and mechanical tests. 


\section{FT-IR}

Spectra were acquired in attenuated total reflectance (ATR) mode on the smooth radial surfaces of wood strips under airdry conditions. A torque clamp insured uniform pressure on all specimens. Spectra were recorded with a Nicolet 6700 spectrometer (Thermo Fisher Scientific Inc., MA, USA), between 4000 and $600 \mathrm{~cm}^{-1}$, at a resolution of $4 \mathrm{~cm}^{-1}$. Each measure is the average of 64 specimen scans, with "blanks" consisting of 64 background scans each time. Spectra were simply baseline-corrected in the $3750-2750 \mathrm{~cm}^{-1}$ and 1800 $780 \mathrm{~cm}^{-1}$ (fingerprint) regions, and averaged (first between specimens of a given wood type and species, then for CW and NW over the three species), with the software "Omnic 8.1" (Thermo Fischer Scientific). Differences were studied on the basis of bands potentially relevant for comparison of $\mathrm{CW}$ and NW (Faix 1991; Gindl 2002; Schwanninger et al. 2004; Altaner et al. 2009).

\section{Standard physical and mechanical measurements}

Routine methods of CIRAD for standard measurements of mechanical and physical properties were applied (Ruelle et al. 2007). Mechanical properties and air-dry specific gravity $(\gamma$, calculated from mass and volume of specimens) were determined in an equilibrium state at $20 \pm 1{ }^{\circ} \mathrm{C}$ and $65 \pm 2 \% \mathrm{RH}$ [moisture content (MC) was in the range of 11 to $12 \%$ ].

Dynamic modulus of elasticity $\left(E^{\prime}\right)$ Longitudinal $E^{\prime}$ was measured on air-dry wood by natural vibrations (Bordonné 1989) on the long rods $\left(360 \times 20 \times 20 \mathrm{~mm}^{3}\right)$. In this method, $E^{\prime}$ is determined through the Timoshenko theory, i.e., the shear and rotary inertia is taken into account (Brancheriau and Baillères 2002). Tests also provide an evaluation of the anisotropy between axial $E^{\prime}$ and in-plane shear modulus $\left(E^{\prime} / G_{L T}^{\prime}\right)$.

Compression strength Crushing strength in compression parallel to the grain was measured (ISO standard 3132:1975) on specimens $\left(20 \times 20 \times 60 \mathrm{~mm}^{3} ; \mathrm{R} \times \mathrm{T} \times \mathrm{L}\right)$ taken from rods used for $E^{\prime}$ measurement (Figure 2). Instrument: MTS 20/M universal testing machine equipped with a $10 \mathrm{kN}$ load cell. Load was applied parallel to the grain at a rate of $0.6 \mathrm{~mm} \mathrm{~min}^{-1}$.

Shrinkage Shrinkages in $\mathrm{L}, \mathrm{R}$, and $\mathrm{T}$ direction were calculated based on the ratio of the dimensional variation in each direction between saturated and anhydrous states. Fiber saturation point (FSP) was assessed by the intersection point of volumetric shrinkage. Initial dimensions of specimens, also taken from rods used for $E^{\prime}$ measurements, were $20 \times 20 \times 50 \mathrm{~mm}^{3}(\mathrm{R}, \mathrm{T}, \mathrm{L})$ for $\mathrm{L}$ shrinkage and $F S P$, and $20 \times 20 \times 10 \mathrm{~mm}^{3}(\mathrm{R}, \mathrm{T}, \mathrm{L})$ for $\mathrm{R}$ and $\mathrm{T}$ shrinkage.

\section{Measurement of vibrational properties on strips}

All tests were performed after at least 3 weeks of stabilization under controlled conditions at $20 \pm 1{ }^{\circ} \mathrm{C}$ and $65 \pm 2 \% \mathrm{RH}$. There were no significant differences in $\mathrm{MC}$ between $\mathrm{CW}$ and NW. Measurements were made by non-contact forced-released flexural vibrations of free-free bars, on the thin strips $\left(12 \times 2 \times 150 \mathrm{~mm}^{3} ; \mathrm{R} \times \mathrm{T} \times \mathrm{L}\right)$. Specimens were made to vibrate through an electromagnet facing a thin iron plate $(0.02 \mathrm{~g})$ glued on one end of the strip, and their displacement at a belly of vibration was measured by a laser triangulation sensor. Vibration emission and detection were computer-driven by means of a specific development in Labview Software (Brémaud 2006; Brémaud et al. 2012). Specific dynamic modulus of elasticity $\left(E^{\prime} / \gamma\right)$ was deduced from the first resonant frequency according to the Euler-Bernoulli equation. Damping coefficient tan $\delta$ was measured both by the 'quality factor' (bandwidth at half power in the frequency domain) and by the logarithmic decrement of amplitude after stopping the excitation (in the time domain). Frequencies were in the range of $200-400 \mathrm{~Hz}$. Three repetitions were made for each specimen, and the mean error was $\leq 5 \%$.

\section{Results and discussion}

\section{Differences between CW and NW in general}

The mean values of structural, physical and mechanical properties measured on rods are presented in Table 1. The results are in agreement with those of the literature (e.g., Timell 1986). CW has a higher MFA, specific gravity, L shrinkage and compression strength, but lower FSP, R and T shrinkage and axial Young's and specific modulus. Axial-toshear anisotropy $\left(E^{\prime} / G^{\prime}{ }_{L T}\right)$ is also lower in $\mathrm{CW}$ with the same amplitude of differences as observed for $E^{\prime} / \gamma$. However, due to the high slenderness of the strips (length/height ratio of 75 ), $E^{\prime} / \gamma$ measured on rods (by Timoshenko theory) or on strips (by Bernoulli theory) were identical both for NW and CW (Figure 3a) independently of their different values of $E^{\prime} / G^{\prime}{ }_{L T}$ The fact that determinations of $\gamma, E^{\prime}$ and $E^{\prime} / \gamma$ were equivalent in tests both on rods and on strips allows further

Table 1 Comparison between compression wood (CW) and normal wood (NW) in terms of average values of structural, physical and mechanical properties measured on air-dry rods.

\begin{tabular}{|c|c|c|c|c|c|c|c|c|c|c|c|c|}
\hline Rods & & $\begin{array}{c}\text { d pith } \\
(\mathrm{cm})\end{array}$ & $M F A\left(^{\circ}\right)$ & $\gamma$ & $\begin{array}{c}E_{L}^{\prime} \\
(\mathrm{GPa})\end{array}$ & $\begin{array}{l}E_{L}^{\prime} / \gamma \\
(\mathrm{GPa})\end{array}$ & $E^{\prime} / G_{L T}^{\prime}$ & $\begin{array}{l}\text { Comp. } \\
\text { (MPa) }\end{array}$ & $\begin{array}{c}F S P \\
(\%)\end{array}$ & $\begin{array}{c}R s h r . \\
(\%)\end{array}$ & $\begin{array}{c}T s h r . \\
(\%)\end{array}$ & $\begin{array}{c}\text { L shr. } \\
(\%)\end{array}$ \\
\hline \multirow[t]{2}{*}{$\mathrm{CW}(n=16)$} & Mean & 10.1 & 36.8 & 0.66 & 4.7 & 6.9 & 4.3 & 37.1 & 26.9 & 2.3 & 4.2 & 2.7 \\
\hline & Standard deviation & 3.5 & 5.5 & 0.08 & 1.8 & 2.1 & 1.1 & 9.2 & 1.5 & 0.4 & 1.6 & 1.3 \\
\hline \multirow[t]{2}{*}{ NW $(n=14)$} & Mean & 6.9 & 22.4 & 0.47 & 8.1 & 16.8 & 10.4 & 27.4 & 30.0 & 4.1 & 8.2 & 0.2 \\
\hline & Standard deviation & 2.6 & 5.2 & 0.06 & 2.5 & 3.3 & 3.0 & 7.6 & 1.6 & 0.4 & 1.5 & 0.1 \\
\hline $\mathrm{CW} / \mathrm{NW}$ & Mean & 1.47 & 1.64 & 1.40 & 0.57 & 0.41 & 0.41 & 1.4 & 0.9 & 0.5 & 0.5 & 13.8 \\
\hline
\end{tabular}

d pith, distance to the pith; MFA, mean microfibril angle; $\gamma$, specific gravity; $R, T, L$ shr., radial, tangential and longitudinal shrinkages from green to oven-dry; FSP, fiber saturation point; $E^{\prime}$ and $E^{\prime} / \gamma$, dynamic Young's and specific modulus by Timoshenko theory; $E^{\prime} / G_{L T}^{\prime}$, axial modulus/in-plane shear anisotropic ratio; Comp., crushing strength in compression parallel to the grain. 

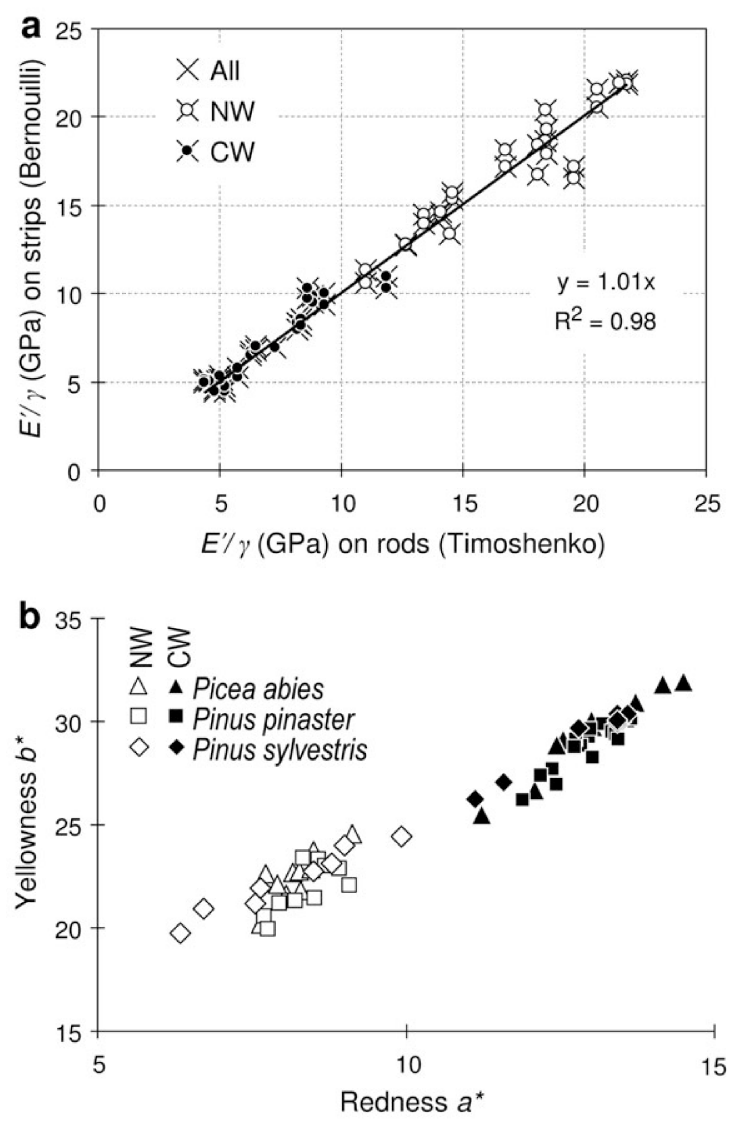

Figure 3 Comparison of specific modulus of elasticity and color between compression wood (CW, filled symbols) and normal wood (NW, open symbols).

(a) Plot of $E^{\prime} / \gamma$ on rods (determined through Timoshenko theory) vs. that on small strips (determined through Bernoulli theory) cut from the same rods; (b) plot of yellowness $\left(b^{*}\right)$ vs. redness $\left(a^{*}\right)$ measured on strips.

comparison of properties determined on the two sizes of specimens.

The mean measured values on strips are presented in Table 2. The lower $E^{\prime} / \gamma$ of $\mathrm{CW}$ is associated with higher $\tan \delta . \mathrm{CW}$ is darker and mostly more colored with a higher contribution of redness $a^{*}$ (Figure $3 \mathrm{~b}$ ), which, when low amounts of extractives are present, is usually ascribed to more lignified, thicker cell-walls, as cellulose and hemicelluloses do not absorb visible light (Hon and Shiraishi
2001). The higher amplitudes of FT-IR bands at $\approx 1600 \mathrm{~cm}^{-1}$ and at $\approx 1510 \mathrm{~cm}^{-1}$, related to aromatic ring skeletal vibrations (Faix 1991; Schwanninger et al. 2004; Altaner et al. 2009), confirmed higher lignin content of CW compared to NW in the samples under study (Figure 4).

Although there is a rather important variability in most properties within each wood type, CW or NW, the differences between $\mathrm{CW}$ and NW were all highly significant (shown by one-way ANOVA). The biggest amplitude of relative differences in physical-mechanical properties between $\mathrm{CW}$ and NW occurred for L shrinkage (as it was close to zero in NW). The next biggest amplitudes of differences are for MFA, specific modulus and elastic anisotropy, followed by redness and $\mathrm{R}$ and $\mathrm{T}$ shrinkages. The difference in damping coefficient is more moderate, nearly twice smaller than differences in $E^{\prime} / \gamma$.

\section{Relationships between $\gamma, E^{\prime}, E^{\prime} / \gamma$, and MFA}

The relationship between $E^{\prime}$ and $\gamma$ is shown in Figure 5a. There are strong differences between CW and NW and there is no simple way to predict $E^{\prime}$ from $\gamma$. On the contrary, the relationship between $E^{\prime} / \gamma$ and MFA (Figure $5 b$ ) is classical and its shape is very similar to that of previous results (e.g., Norimoto et al. 1986; Koponen et al. 1989; Astley et al. 1998; Bergander and Salmén 2002; Yamamoto and Kojima 2002; $\mathrm{Xu}$ and Liu 2004). Empirical constants for the curve shape described by Eq. (1) were fitted to experimental data by optimization with the help of the solver in MS Excel; the best fitting gives the formula:

$E^{\prime} / \gamma=\frac{1}{\left(0.03426 \times \cos ^{4} \phi+0.2053 \times \cos ^{2} \phi \sin ^{2} \phi+0.6797 \times \sin ^{4} \phi\right)}$

If any, a residual difference between $\mathrm{CW}$ and NW that might be linked to variations in the cell wall matrix is hardly noticeable (Figure $5 b$ ). Indeed, it was proposed based on micromechanical models that variations in the content of lignin and hemicelluloses play only a weak role in L elasticity, although some differences in cellulose structure might have a bigger effect (Bergander and Salmén 2002; Xu et al. 2011).

The statistical curve fitting in Eq. (3) is suited for estimating elastic modulus $E^{\prime}$ from $\gamma$ and MFA values (Figure 5c), which explained $77 \%$ of the variability in $E^{\prime}$. Both the calculatedexperimental values relationship and the residual dispersion

Table 2 Comparison between compression wood $(\mathrm{CW})$ and normal wood $(\mathrm{NW})$ in terms of average values of physical, vibrational and colorimetric properties measured on air-dry strips.

\begin{tabular}{|c|c|c|c|c|c|c|c|c|c|c|}
\hline Strips & $\cdot$ & $\gamma$ & $E_{\mathrm{L}}^{\prime}(\mathrm{GPa})$ & $E_{\mathrm{L}}^{\prime} / \gamma(\mathrm{GPa})$ & $\tan \delta_{\mathrm{L}}\left(10^{-3}\right)$ & $L^{*}$ & $a^{*}$ & $b^{*}$ & $C^{*}$ & $h\left(^{\circ}\right)$ \\
\hline \multirow[t]{2}{*}{$\mathrm{CW}(n=32)$} & Mean & 0.66 & 4.8 & 7.1 & 14.2 & 80.4 & 12.9 & 29.0 & 31.8 & 66.0 \\
\hline & Standard deviation & 0.06 & 1.8 & 2.1 & 2.4 & 1.0 & 0.8 & 1.5 & 1.7 & 0.5 \\
\hline \multirow[t]{2}{*}{$\mathrm{NW}(n=28)$} & Mean & 0.48 & 8.3 & 17.1 & 10.5 & 87.5 & 8.2 & 22.2 & 23.7 & 69.7 \\
\hline & Standard deviation & 0.07 & 2.5 & 3.4 & 1.6 & 1.2 & 0.7 & 1.3 & 1.4 & 1.1 \\
\hline CW/NW & Mean & 1.39 & 0.58 & 0.41 & 1.36 & 0.92 & 1.57 & 1.31 & 1.34 & 0.95 \\
\hline
\end{tabular}

$(\gamma)$, specific gravity; $E^{\prime}$ and $E^{\prime} / \gamma$, dynamic Young's and specific modulus by Bernouilli theory; $L^{*}$, lightness; $a^{*}$, redness; $b^{*}$, yellowness; $\left(C *=\sqrt{a^{* 2}+b^{* 2}}\right)$ saturation/chromaticity; $h, \arctan \left(b^{*} / a^{*}\right)$ hue angle. 


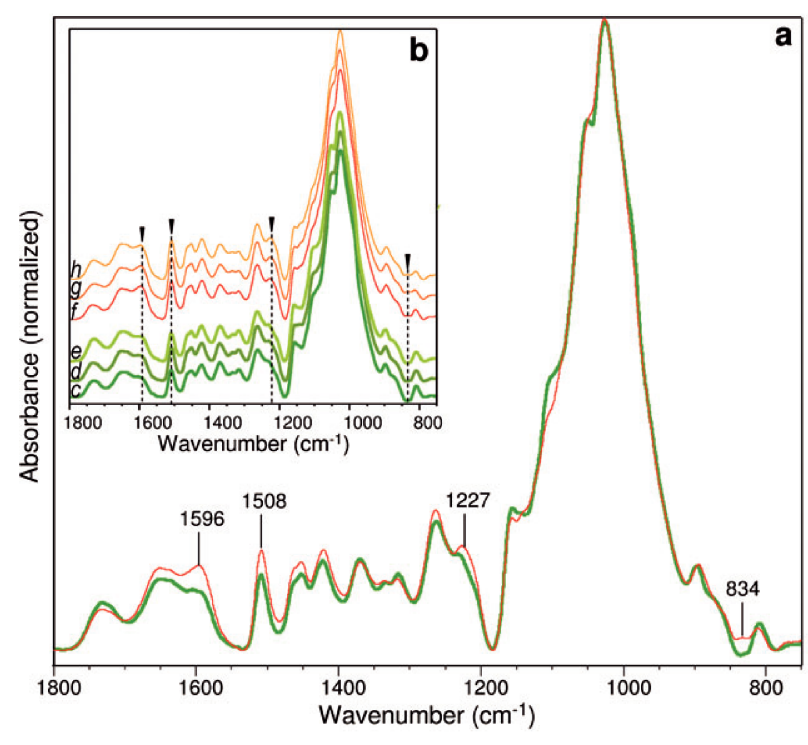

Figure 4 Baseline corrected and normalized FT-IR spectra in the fingerprint region from 1800 to $750 \mathrm{~cm}^{-1}$. (a) Mean spectra of normal wood (thick lines) and compression wood (thin lines) averaged over the three wood species indicated in Figure 1; (b) mean spectra of NW $(c, d, e)$ and $\mathrm{CW}(f, g, h)$ for spruce $(c, f)$, maritime pine $(d, g)$ and Scots pine $(e, h)$ averaged over the studied specimens.

were equivalent for $\mathrm{CW}$ and NW. However, residual variability might also express the secondary influence of other factors, such as differences in the proportion of crystalline cellulose MFs, which might differ depending on sample origin (Yamamoto and Kojima 2002), or anatomical parameters such as rounded cell shapes or helical cavities (Timell 1983; Burgert et al. 2004). It may also simply reflect the variability in MFA within specimens (e.g., Sedighi-Gilani et al. 2005).

\section{Relationships between $\tan \delta$, MFA and $E^{\prime} / \gamma$}

Damping coefficient tan $\delta$ is related to MFA (Figure 6a) in a way quite similar to observations of Norimoto et al. (1986) on hinoki wood (Chamaecyparis obtusa). However, there is an important scattering in the tan $\delta$-MFA relationship in the present results. Although the range of MFA considered here was larger $\left(10^{\circ}-45^{\circ}\right)$ than in previous data on hinoki wood $\left(5^{\circ}-25^{\circ}\right)$, the observed maximum of $\tan \delta$ is not much higher (0.018 vs. 0.015). By combining Eq. (2) (standard trend between $\tan \delta$ and $\left.E^{\prime} / \gamma\right)$ and Eq. (3) (dependence of $E^{\prime} / \gamma$ on MFA), a predicted relationship between tan $\delta$ and MFA can be drawn (Figure 6a). In this way, the shape of the relationship is closer to the theoretical dependence of $\tan \delta$ on changing orientations (Norimoto et al. 1986; Obataya et al. 2000; Brémaud et al. 2011b). Looking at this predictive curve, the damping behaviors of $\mathrm{CW}$ and $\mathrm{NW}$ are different.

The direct observation (Figure 6b) of the relationship between $\tan \delta$ and $E^{\prime} / \gamma$ (which is closely related to MFA and thus gives similar information) is a good alternative, as scale effects between test specimens and MFA observations are circumvented. NW from the 3 species followed a single, simi-
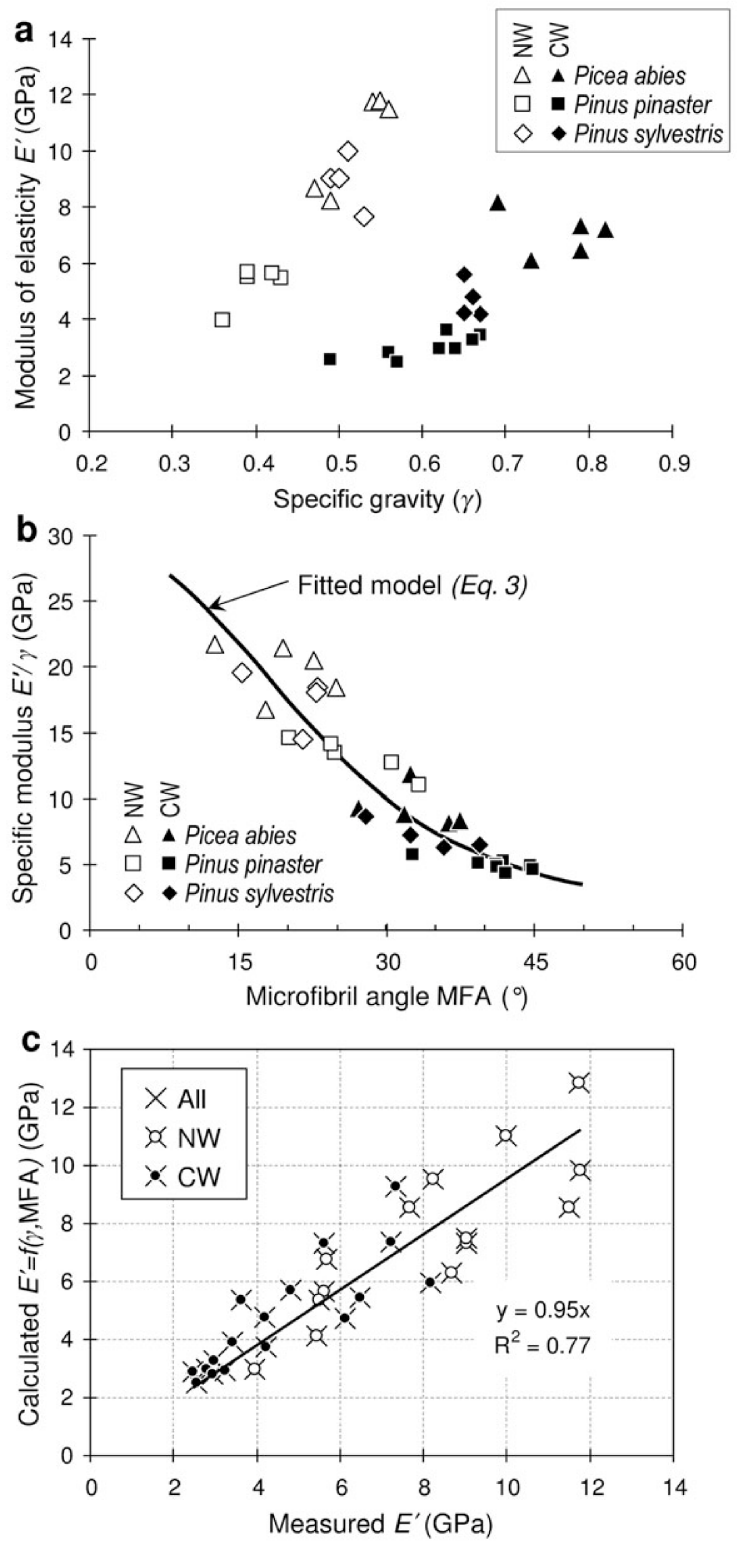

Figure 5 Relationships between modulus of elasticity, specific gravity and microfibril angle.

(a) $E^{\prime}$ vs. $\gamma$ as measured on rods; (b) $E^{\prime} / \gamma$ vs. MFA as measured on rods; (c) calculated $E^{\prime}$ data (taking into account $\gamma$, and MFA through Eq. (3) vs. experimental data of $E^{\prime}$.

lar trend which, if extended towards higher values of $E^{\prime} / \gamma$, would join the data for 'resonance' spruce from the literature (Yano et al. 1992; Haines 2000; Bucur 2006; Brémaud 2012). $\mathrm{CW}$ of the three species also followed a common trend, but shifted downwards lower $\tan \delta$ when compared with the trend for NW. When compared to the 'standard' curve from Ono and Norimoto (1983), the curve for NW is above and that for $\mathrm{CW}$ is below the reference. Measured $\tan \delta$ values are proportional to those calculated by this empirical model based on $E^{\prime} / \gamma$ (Figure 6c), with CW being 15\% lower and NW 19\% higher. Values of $\tan \delta$ which are higher than the 'standard' 

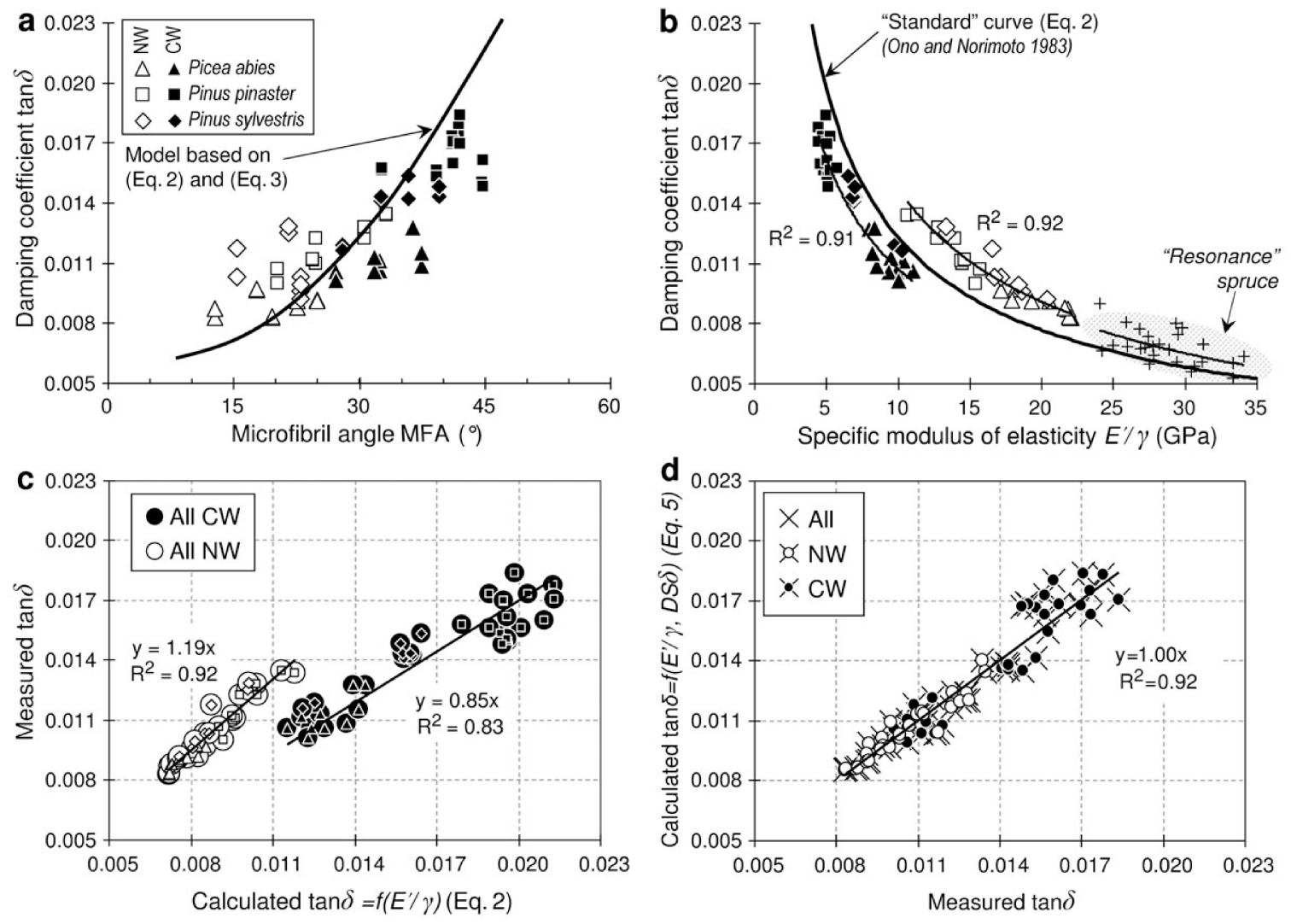

Figure 6 Relationships between damping coefficient $(\tan \delta)$ and microfibril angle or specific modulus of elasticity.

(a) $\tan \delta$ vs. MFA; (b) tan $\delta$ vs. $E^{\prime} / \gamma$ measured on strips; (c) Experimental values of tan $\delta$ vs. those of statistical model (Eq. 2) based only on $E^{\prime} / \gamma$; (d) tan $\delta$ calculated by statistical model [Eq. (5)] based on $E^{\prime} / \gamma$ and chemistry-related indicator DS $\delta$, vs. experimental $\tan \delta$.

are often observed in NW of Pinaceae (Brémaud et al. 2009). There are some small differences between the three species, but these are not highly significant. At equivalent $E^{\prime} / \gamma, \mathrm{CW}$ had damping values $34 \%$ lower than NW. This strong difference is expected to be due to differences in chemical composition. According to simulations based on cell wall models (Akitsu et al. 1993; Obataya et al. 2000), vertical shifts in the $\tan \delta-E^{\prime} / \gamma$ representation are essentially related to changes in matrix viscosity. The deviation from standard damping [DS $\delta$, Eq. (4)], that is, the percentage difference from the standard curve, can serve as an empirical indicator accounting for such putative chemical differences, as it was previously introduced for the effect of extractives (Brémaud et al. 2010b, 2012).

$D S \delta=\frac{\tan \delta_{i}-\tan \delta_{s}}{\tan \delta_{s}}$

Where $\tan \delta_{i}$ is the measured damping coefficient of a given sample, and $\tan \delta_{s}\left(=10^{-1.23} \times\left(E^{\prime} / \gamma\right)^{-0.68}\right)$ is the standard trend from Eq. (2).

The damping coefficient can then be estimated from specific modulus $E^{\prime} / \gamma$ and DS $\delta$ according to Eq. (5):

$\tan \delta_{p}=\tan \delta_{s} \times(1+D S \delta)$ where $\tan \delta_{p}$ is the predicted damping coefficient, which, in the present case, accounts for $92 \%$ of the measured variability in damping (Figure 6d).

\section{Role of variations in matrix chemistry on viscoelastic properties}

The changes between NW and CW may be quite gradual ( $\gamma$ or MFA) or more abrupt (amount and structure of lignin). Therefore, some properties may be distributed along a continuum, and others not, depending on their predominant affecting factors. Gindl (2002) found that, despite a higher MFA, the more abundant and condensed lignin leads to increased compression strength parallel to the grain in $\mathrm{CW}$, which was also found in the present study, although $\gamma$ still had a dominant effect.

Concerning vibrational properties, the important residual differences in $\tan \delta$ between $\mathrm{CW}$ and NW, after taking MFA into account, can be clearly interpreted as an influence of the changes in polymers of the cell wall matrix. On the contrary, it was not possible to detect a convincing influence of matrix composition on $E^{\prime} / \gamma$, which mostly depends on MFA. These results are similar to those from other studies focused on extractives from several species (Yano 1994; Matsunaga 
et al. 1999; Obataya et al. 1999; Brémaud et al. 2010a,b, 2011b; Minato et al. 2010). Between CW and NW, differences in extractives are generally negligible compared to differences in matrix polymers.

Lignin is known to be responsible for the main thermalsoftening transition in water-saturated wood, which has notably been studied by DMA (dynamic mechanical analysis) (Salmén 1984; Furuta et al. 1997, 2000, 2008, 2010). Dynamic IR spectroscopy (in dry conditions) also indicates that lignin exhibits a much more viscoelastic behavior than carbohydrates do (Akerholm and Salmén 2003). Thus, an increased lignin/cellulose ratio in $\mathrm{CW}$ should result in an increased viscosity, instead of the reduction which is observed in the present paper after separating the effect of MFA variations.

Samples of the three trees/species studied in the present work exhibit the generally known characteristic differences in lignin between CW and NW, according to FT-IR spectra (Figure 4). Larger bands at 1600 and at $510 \mathrm{~cm}^{-1}$, related to aromatic skeletal vibrations (Faix 1991; Schwanninger et al. 2004), is for higher lignin content in CW. The smaller ratio between the bands at 1510 and $1600 \mathrm{~cm}^{-1}$ in $\mathrm{CW}$ spectra indicates a lower proportion in guaiacyl (G) units (Faix 1991; Gindl 2002; Schwanninger et al. 2004), while a small band at $834 \mathrm{~cm}^{-1}$, present in CW but absent in NW spectra, is related to $p$-hydroxyphenyl $(\mathrm{H})$ units (Faix 1991; Gindl 2002). Both spectral features indicate that the $\mathrm{CW}$ lignin consists of $\mathrm{G}$ and $\mathrm{H}$ units (i.e., is an HG lignin) while NW lignin in conifers is a $\mathrm{G}$ lignin. $\mathrm{CW}$ lignins are also known to be more condensed (Timell 1982; Yeh et al. 2005, 2006; Nanayakkara et al. 2009), which is probably reflected by the higher band at $1227 \mathrm{~cm}^{-1}$ (Schwanninger et al. 2004).

In the quasi-static domain, a lower S/G (syringyl/guaiacyl) ratio was related to lower relative creep at similar MFA levels, in an unusual wood growth in branches of a specific hardwood (HW) (Wang et al. 2010). Thermoactivated dynamic mechanical studies on water-saturated wood have shown that an increase in the cross-linking density of lignin, brought about by thermal and/or chemical treatments, results in a shift of the main softening transition of wood towards higher temperatures (Olsson and Salmén 1992; Placet et al. 2008; Assor et al. 2009). Similarly, in untreated wood, softening temperatures are lower in HW of the temperate zone, having GS lignins, than in softwoods (SW) of the temperate zone with G lignins (Olsson and Salmén 1992, Furuta et al. 2008). Tropical HW may contain very different $\mathrm{S} / \mathrm{G}$ ratios and lignin contents (Sarkanen and Ludwig 1971; Wu 1993); their softening temperatures are often in between those found for temperate zone HW and SW (Furuta et al. 2008). Olsson and Salmén (1997) found a nearly linear decrease of softening temperature of wet wood as a function of methoxy group contents, which can be considered as 'bulking' groups preventing cross-linking via chemical linkages in position 5 of the aromatic ring. CWs of two Pinus species had both the highest softening temperatures and activation energies, and the lowest methoxy group contents (Olsson and Salmén 1997). However, in another study (Placet et al. 2007), the softening temperature of CW was lower than that of NW. Probably, the softening temperature of bulk wood results from interactions between the polymer structure, supramolecular architecture of wood components in the cell wall, and the topochemistry of the tissue. Molecular modeling, coupled with experiments on synthetic polymers of lignin precursors have also shown that higher methoxy contents led to more flexible polymers (Russell et al. 2000). In summary, the results of the present work which show that more condensed $\mathrm{CW}$ lignins with elevated $\mathrm{H}$ contents lead to lower wood tan $\delta$ at a similar MFA/stiffness level, are consistent with data of the literature. In short, condensed lignins with less methoxy groups lead to decreased wood viscosity.

The influence of lignin on viscoelasticity in the audiofrequencies range of air dried wood had hitherto only been hypothesized, but had never been assessed experimentally. Interestingly, damping deviations due to lignin found in the present paper were of lower absolute amplitude (approx. $34 \%$ ) than those observed in other studies in the case of some particular extractives (up to $\geq 45 \%$ ). Differences between species in the amount and chemical structure of lignin and of extractives could explain damping characteristics which are observed between temperate or tropical zones, and between botanical groups (Brémaud et al. 2009, 2012; Brémaud 2012).

\section{Conclusion}

The deviating properties of CW and NW within a single tree offer a good opportunity for studying the influence of specific gravity $(\gamma)$, MFA, and cell-wall matrix composition and chemistry on wood viscoelastic properties. The present work focused on viscoelastic vibrational tests of three wood species, and interrelations with MFA, physical-mechanical and IR-spectroscopic characteristics were observed. The results showed that:

- Differences in all properties between CW and NW are highly significant. Amplitudes of absolute differences rank in the order: axial shrinkage $>M F A \geq$ specific modulus of elasticity $\left(E^{\prime} / \gamma\right)$ and axial-to-shear anisotropy $\geq$ color intensity and redness $\geq$ transverse shrinkage $>$ Young's modulus $\left(E^{\prime}\right) \geq \gamma \geq$ compressive strength $\geq$ damping coefficient $(\tan \delta$ ).

- Specific modulus of elasticity $\left(E^{\prime} / \gamma\right)$ decreases with increasing MFA, following a common trend between CW and NW. Young's modulus $\left(E^{\prime}\right)$ can be predicted from $\gamma$ and MFA, and the residual variability does not appear to be linked to wood type nor to changes in polymer matrix in the cell walls.

- Damping coefficient $(\tan \delta)$ tends to increase with MFA, but MFA as a parameter is not sufficient to describe changes in $\tan \delta$ between NW and CW. After taking into account the effect of MFA (through the $\tan \delta-E^{\prime} / \gamma$ relationship), it appears that CW has a lower (by approx. 34\%) normalized damping than NW. This can be ascribed to lignin chemistry (as readily visible in FT-IR spectra): more condensed lignins with fewer methoxy groups lead to decreased viscosity. 
The present results are consistent with previous findings on different materials and in other physical domains, particularly in thermal-softening studies. Obviously, the effects of matrix polymers chemistry on macroscopic viscoelasticity are in relation to the supramolecular structure at the microand nano-level of the cell wall. It would be interesting to verify if differences in lignin structure could also be involved in taxonomy-related damping characteristics.

\section{Acknowledgements}

The authors thank P. Perré in LERFoB, INRA ENGREFAgroParisTech Nancy, for providing access to FT-IR spectroscopy, and P. Lu for practical advice. Useful comments by O. Faix, editor in chief, are also gratefully acknowledged.

\section{References}

Akerholm, M., Salmén, L. (2003) The oriented structure of lignin and its viscoelastic properties studied by static and dynamic FT-IR spectroscopy. Holzforschung 57:459-465.

Akitsu, H., Gril, J., Norimoto, M. (1993) Uniaxial modelling of vibrational properties of chemically modified wood. Mokuzai Gakkaishi 39:258-264.

Alméras, T., Thibaut, A., Gril, J. (2005) Effect of circumferential heterogeneity of wood maturation strain, modulus of elasticity and radial growth on the regulation of stem orientation in trees. Trees 19:457-467.

Altaner, C., Hapca, A., Knox, J.P., Jarvis, M.C. (2007) Detection of $\beta$-1-4-galactan in compression wood of Sitka spruce [Picea sitchensis (Bong.) Carrière] by immunofluorescence. Holzforschung 61:311-316.

Altaner, C.M., Tokareva, E.N., Wong, J.C.T., Hapca, A.I., McLean, J.P., Jarvis, M.C. (2009) Measuring compression wood severity in spruce. Wood Sci. Technol. 43:279-290.

Assor, C., Placet, V., Chabbert, B., Habrant, A., Lapierre, C., Pollet, B., Perré, P. (2009) Concomitant changes in viscoelastic properties and amorphous polymers during the hydrothermal treatment of hardwood and softwood. J. Agric. Food Chem. 57: 6830-6837.

Astley, R.J., Stol, K.A., Harrington, J.J. (1998) Modelling the elastic properties of softwood. Holz Roh-Werkst. 56:43-50.

Bergander, A., Salmén, L. (2002) Cell wall properties and their effects on the mechanical properties of fibers. J. Mater. Sci. 37:151-156.

Bordonné, P.A. (1989) Module dynamique et frottement intérieur dans le bois. Mesures sur poutres flottantes en vibrations naturelles. PhD, Institut National Polytechnique de Lorraine, Nancy, France.

Brancheriau, L., Baillères, H. (2002) Natural vibration analysis of clear wooden beams: a theoretical review. Wood Sci. Technol. $36: 347-365$

Brémaud, I. (2006) Diversité des bois utilisés ou utilisables en facture d'instruments de musique. PhD, Mechanics. Université Montpellier II, France.

Brémaud, I. (2012) Acoustical properties of wood in string instruments soundboards and tuned idiophones: biological and cultural diversity. J. Acoust. Soc. Am. 131:807-818.

Brémaud, I., Minato, K., Thibaut, B. (2009) Mechanical damping of wood as related to species classification: a preliminary survey.
In: 6th Plant Biomechanics Conference. Ed. Thibaut, B. UMR EcoFoG, Cayenne, Kourou, French Guyana. pp. 536-542.

Brémaud, I., Cabrolier, P., Gril, J., Clair, B., Gérard, J., Minato, K., Thibaut, B. (2010a) Identification of anisotropic vibrational properties of Padauk wood with interlocked grain. Wood Sci. Technol. 44:355-367.

Brémaud, I., Minato, K., Langbour, P., Thibaut, B. (2010b) Physicochemical indicators of the inter-specific variability in vibration damping of wood. Ann. For. Sci. 67:707(8p).

Brémaud, I., Amusant, N., Minato, K., Gril, J., Thibaut, B. (2011a) Effect of extractives on vibrational properties of African Padauk (Pterocarpus soyauxii Taub.). Wood Sci. Technol. 45:461-472.

Brémaud, I., Gril, J., Thibaut, B. (2011b) Anisotropy of wood vibrational properties: dependence on grain angle and review of literature data. Wood Sci. Technol. 45:735-754.

Brémaud, I., El Kaïm, Y., Guibal, D., Minato, K., Thibaut, B., Gril, J. (2012) Characterization and categorization of the diversity in vibrational properties between 98 wood types. Ann. For. Sci. 69:373-386.

Bucur, V. Acoustics of wood. Springer-Verlag, Berlin, Heidelberg, New York, 2006.

Burgert, I., Frühmann, K., Keckés, J., Fratzl, P., Stanzl-Tschegg, S. (2004) Structure-function relationships of four compression wood types: micromechanical properties at the tissue and fibre level. Trees 18:480-485.

Diaz-vaz, J.E., Ananias, R.A., Rodriguez, S., Torres, M., Fernandez, A., Poblete, H. (2009) Compression wood in Pinus radiata II: density and chemical composition. Maderas Cienc. Tecnol. 11:139-151.

Donaldson, L.A., Grace, J.C., Downes, G.M. (2004) Within-tree variation in anatomical properties of compression wood in radiata pine. IAWA J. 25:253-271.

Faix, O. (1991) Classification of lignins from different botanical origins by FT-IR spectroscopy. Holzforschung 45 (Suppl): 21-27.

Furuta, Y., Aizawa, H., Yano, H., Norimoto, M. (1997) Thermalsoftening of water-swollen wood IV. The effects of chemical constituents of the cell wall on the thermal-softening properties of wood (in Japanese). Mokuzai gakkaishi. 43:725-730.

Furuta, Y., Imanishi, H., Kohara, M., Yokoyama, M., Obata, Y., Kanayama, K. (2000) Thermal-softening of water-swollen wood VII. The effects of lignin (in Japanese). Mokuzai Gakkaishi. 46:132-136.

Furuta, Y., Nakajima, M., Nakatani, T., Kojiro, K., Ishimaru, Y. (2008) Effects of lignin on the thermal-softening properties of the water-swollen wood (in Japanese). Zairyo-J. Soc. Mater. Sci. Jpn. 57:344-349.

Furuta, Y., Nakajima, M., Nakanii, E., Ohkoshi, M. (2010) The effects of lignin and hemicellulose on thermal-softening properties of water-swollen wood (in Japanese). Mokuzai Gakkaishi. 56:132-138.

Gindl, W. (2002) Comparing mechanical properties of normal and compression wood in Norway Spruce: the role of lignin in compression parallel to the grain. Holzforschung 56:395-401.

Gindl, W., Teischinger, A. (2003) Comparison of the TL-shear strength of normal and compression wood of european larch. Holzforschung 57:421-426.

Haines, D.W. (2000) The essential mechanical properties of wood prepared for musical instruments. Catgut Acoust. Soc. J. 4:20-32.

Hänninen, T., Tukiainen, P., Svedström, K., Serimaa, R., Saranpää, P., Kontturi, E., Hughes, M., Vuorinen, T. (2012) Ultrastructural evaluation of compression wood-like properties of common juniper (Juniperus communis L.). Holzforschung 66:389-395. 
Hon, D.N.S., Shiraishi, N. Wood and cellulosic chemistry. Marcel Dekker, New York, Basel, 2001.

Jungnikl, K., Koch, G., Burgert, I. (2008) A comprehensive analysis of the relation of cellulose microfibril orientation and lignin content in the S2 layer of different tissue types of spruce wood (Picea abies (L.) Karst.). Holzforschung 62:475-480.

Koponen, S., Toratti, T., Kanerva, P. (1989) Modelling longitudinal elastic and shrinkage properties of wood. Wood Sci. Technol. 23:55-63.

Matsumoto, T. (1961) Studies on the dynamic modulus E by transverse vibration. VI. On the dynamic modulus $\mathrm{E}$ and the damping of vibrations in compression wood. Mokuzai Gakkaishi 7:90-95.

Matsunaga, M., Minato, K., Nakatsubo, F. (1999) Vibrational property changes of spruce wood by impregnation with water-soluble extractives of pernambuco (Guilandina echinata Spreng.). J. Wood Sci. 45:470-474.

Minato, K., Konaka, Y., Brémaud, I., Suzuki, S., Obataya, E. (2010) Extractives of muirapiranga (Brosimun sp.) and its effects on the vibrational properties of wood. J. Wood Sci. 56:41-46.

Nanayakkara, B. (2007) Chemical characterisation of compression wood in plantation grown Pinus radiata. $\mathrm{PhD}$, University of Waikato, Hamilton, New Zealand.

Nanayakkara, B., Manley-Harris, M., Suckling, I.D., Donaldson, L.A. (2009) Quantitative chemical indicators to assess the gradation of compression wood. Holzforschung 63:431-439.

Norimoto, M., Ono, T., Watanabe, Y. (1984) Selection of wood used for piano soundboards (in Japanese). J. Soc. Rheol. Jpn. 12:115-119.

Norimoto, M., Tanaka, F., Ohogama, T., Ikimune, R. (1986) Specific dynamic Young's modulus and internal friction of wood in the longitudinal direction (in Japanese). Wood Res. Techn. Notes 22:53-65.

Obataya, E., Umezawa, T., Nakatsubo, F., Norimoto, M. (1999) The effects of water-soluble extractives on the acoustic properties of reed (Arundo donax L.). Holzforschung 53:63-67.

Obataya, E., Ono, T., Norimoto, M. (2000) Vibrational properties of wood along the grain. J. Mater. Sci. 35:2993-3001.

Olsson, A.-M., Salmén, L. (1992) Viscoelasticity of in situ lignin as affected by structure: Softwood vs. hardwood. In: Viscoelasticity of biomaterials. American Chemical Society, Washington. pp. 133-143.

Olsson, A.-M., Salmén, L. (1997) The effect of lignin composition on the viscoelastic properties of wood. Nord. Pulp Pap. Res. J. 3:140-144.

Önnerud, H. (2003) Lignin structures in normal and compression wood. Evaluation by thioacidolysis using ethanethiol and methanethiol. Holzforschung 57:377-384.

Ono, T., Norimoto, M. (1983) Study on Young's modulus and internal friction of wood in relation to the evaluation of wood for musical instruments. Jpn J. Appl. Phys. 22:611-614.

Placet, V., Passard, J., Perré, P. (2007) Viscoelastic properties of green wood across the grain measured by harmonic tests in the range $0-95^{\circ} \mathrm{C}$ : Hardwood vs. softwood and normal wood vs. reaction wood. Holzforschung 61:548-557.

Placet, V., Passard, J., Perré, P. (2008) Viscoelastic properties of wood across the grain measured under water-saturated conditions up to $135^{\circ} \mathrm{C}$ : evidence of thermal degradation. J. Mater. Sci. 43:3210-3217.

Ruelle, J., Beauchêne, J., Thibaut, A., Thibaut, B. (2007) Comparison of physical and mechanical properties of tension and opposite wood from ten tropical rainforest trees from different species. Ann. For. Sci. 64:503-510.
Russell, W.R., Forrester, A.R., Chesson, A. (2000) Predicting the macromolecular structure and properties of lignin and comparison with synthetically produced polymers. Holzforschung 54: 505-510.

Salmén, L. (1984) Viscoelastic properties of in situ lignin under water-saturated conditions. J. Mater. Sci. 19:3090-3096.

Salmén, L., Burgert, I. (2009) Cell wall features with regard to mechanical performance. A review. COST Action E35 2004-2008: Wood machining - micromechanics and fracture. Holzforschung 63:121-129.

Sarkanen, K.V., Ludwig, C.H. Eds. Lignins - Occurence, Formation, Structure and Reactions. Wiley-Interscience, New York, 1971.

Schwanninger, M., Rodrigues, J.C., Pereira, H., Hinterstoisser, B. (2004) Effects of short-time vibratory ball milling on the shape of FT-IR spectra of wood and cellulose. Vibr. Spectrosc. 36: 23-40.

Sedighi-Gilani, M., Sunderland, H., Navi, P. (2005) Microfibril angle non-uniformities within normal and compression wood tracheids. Wood Sci. Technol. 39:419-430.

Senft, J.F., Bendtsen, B.A. (1985) Measuring microfibrillar angles using light microscopy. Wood Fiber Sci. 17:564-567.

Stevanic, J.S., Salmén, L. (2009) Orientation of the wood polymers in the cell wall of spruce wood fibres. Holzforschung 63 : 497-503.

Tarmian, A., Perré, P. (2009) Air permeability in longitudinal and radial directions of compression wood of Picea abies L. and tension wood of Fagus sylvatica L. Holzforschung 63:352-356.

Timell, T.E. (1973) Studies on opposite wood in conifers Part I: Chemical composition. Wood Sci. Technol. 7:1-5.

Timell, T.E. (1982) Recent progress in the chemistry and topochemistry of compression wood. Wood Sci. Technol. 16:83-122.

Timell, T.E. (1983) Origin and evolution of compression wood. Holzforschung 37:1-10.

Timell, T.E. Compression wood in Gymnosperms. Springer Verlag, Berlin, New York, 1986.

Wang, Y., Gril, J., Clair, B., Minato, K., Sugiyama, J. (2010) Wood properties and chemical composition of the eccentric growth branch of Viburnum odoratissimum var. awabuki. Trees 24:541-549.

Wu, J. (1993) Variation in the distribution of guaiacyl and syringyl lignin in hardwoods (in Japanese). Bull. Fac. Agric. Hokkaido Univ. 18:219-268.

Xu, P., Liu, H. (2004) Models of microfibril elastic modulus parallel to the cell axis. Wood Sci. Technol. 38:363-374.

Xu, P., Liu, H., Donaldson, L.A., Zhang, Y. (2011) Mechanical performance and cellulose microfibrils in wood with high S2 microfibril angles. J. Mater. Sci. 46:534-540.

Yamamoto, H., Kojima, Y. (2002) Properties of cell wall constituents in relation to longitudinal elasticity of wood. Part 1 . Formulation of the longitudinal elasticity of an isolated wood fiber. Wood Sci. Technol. 36:55-74.

Yamashita, S., Yoshida, M., Yamamoto, H. (2009) Relationship between development of compression wood and gene expression. Plant Sci. 176:729-735.

Yano, H. (1994) The changes in the acoustic properties of Western Red Cedar due to methanol extraction. Holzforschung 48:491-495.

Yano, H., Matsuoka, I., Mukudai, J. (1992) Acoustic properties of wood for violins. Mokuzai gakkaishi. 38:122-127.

Yeh, T.-F., Goldfarb, B., Chang, H.-M., Peszlen, I., Braun, J.L., Kadla, J.F. (2005) Comparison of morphological and chemical properties between juvenile wood and compression wood of loblolly pine. Holzforschung 59:669-674. 
Yeh, T.-F., Braun, J.L., Goldfarb, B., Chang, H.-M., Kadla, J.F. (2006) Morphological and chemical variations between juvenile wood, mature wood, and compression wood of loblolly pine (Pinus taeda L.). Holzforschung 60:1-8.

Yoshizawa, N., Ohba, H., Uchiyama, J., Yokota, S. (1999) Deposition of lignin in differentiating xylem cell walls of normal and compression wood of Buxus microphylla var. insularis Nakai. Holzforschung 53:156-160.

Received September 20, 2011. Accepted June 12, 2012. Previously published online July 18, 2012. 